\title{
Conhecimentos sobre sexualidade em adolescentes inseridos num projeto de intervenção social
}

\section{Knowledge about sexuality of adolescents included in a social intervention project}

\author{
Solange da Ponte*, Carla Rocha*, Suzana Nunes Caldeira** \\ *Associação para o Planeamento Familiar e Saúde Sexual e Reprodutiva-Açores, ** Universidade dos Açores
}

\begin{abstract}
Resumo
A promoção de estilos de vida saudáveis durante a adolescência, que segundo a Organização Mundial de Saúde ocorre entre os 10 e os 19 anos, nomeadamente no que concerne à saúde sexual e reprodutiva, é um objetivo fundamental para o desenvolvimento das pessoas e das comunidades. Pretendendo contribuir para este objetivo, foi pensado um Atelier formativo de educação afetivosexual para jovens, estruturado em 10 sessões de 90 minutos cada, recorrendo a metodologias ativas, tais como debates, brainstorming, dinâmicas e reflexão em grupo. Frequentaram o Atelier 14 jovens de idades compreendidas entre 14 e 19 anos. Os resultados, embora incipientes, são encorajadores.

Palavras-Chave: sexualidade, jovens, formação, projeto
\end{abstract}

\begin{abstract}
The promotion of healthy lifestyles during adolescence, which according to the World Health Organization occurs between the ages of 10 and 19 years, particularly with regard to sexual and reproductive health, is a fundamental objective for the development of people and communities. Intending to contribute to this goal, it was planned a formative Atelier of affective-sexual education for young people, structured in 10 sessions of 90 minutes, using active methodologies, through pedagogical techniques such as debates, brainstorming, dynamics and group reflection 14 young people between the ages of 14 and 19 participated in the Atelier.

Keywords: sexuality, young, training, project
\end{abstract}

\section{Introdução}

A Associação para o Planeamento Familiar e Saúde Sexual e Reprodutiva - Açores (APFSSR-Açores) é uma Associação Regional que tem como missão "ajudar as pessoas a fazerem escolhas livres e responsáveis na sua vida sexual e reprodutiva". $\mathrm{Na}$ sua ação tem desenvolvido um trabalho com jovens no âmbito da educação afetivo-sexual, tanto em contexto da educação formal como não formal, e os seus profissionais têm-se sentido desafiados a efetuar uma reflexão sobre as práticas realizadas, nomeadamente em termos de sustentação científica e adequação das metodologias de intervenção ao público-jovem.

É neste contexto de regulação de práticas que, a partir da observação direta, resultante do contacto com os jovens, aliada a um conhecimento que advém do trabalho em rede com outras entidades, surgiu a ideia da criação de programas de educação não-formal, longitudinais e de proximidade aos jovens em situação de maior vulnerabilidade, na ilha de São Miguel, Açores, com vista à prevenção de comportamentos de risco.

Assim, a APFSSR-Açores pretende ir além da promoção de competências relacionadas com o desenvolvimento sexual, apostando no desenvolvimento de competências para a vida. Como sintetizado em Monteiro (2011), a investigação nacional e internacional afirma a eficácia de programas de treino de competências para a vida com adolescentes em vários domínios, como a prevenção de comportamentos de risco, incluindo os de índole sexual, atraso do início do uso de drogas, melhoria do desempenho académico, controlo da agressividade e promoção do ajustamento social, e melhoria do desempenho académico. No fundo, trata-se da educação para comportamentos saudáveis e para a promoção da saúde dos adolescentes.

\section{Promoção da saúde com adolescentes}

Atualmente, a saúde é vista como um conceito holístico e positivo que ultrapassa a ausência de doença, sendo assumida como algo mais do que um objetivo de vida: como um recurso pessoal, social e físico para o dia-a-dia (Organização Mundial de Saúde, 2009) e cuja promoção desde idades precoces pode prevenir sérios e dispendiosos problemas para o indivíduo e para a sociedade (Simões, 2010).

A promoção da saúde e do bem-estar pretende reduzir as diferenças existentes nos níveis de saúde das populações e assegurar a equidade de oportunidades e recursos, com vista a capacitá-las para a completa execução do seu potencial de saúde. Para atingir este 
propósito, torna-se necessária uma sólida inserção num meio favorável, acesso à informação, estilos de vida e oportunidades que permitam opções saudáveis (Ministério da Saúde, 2002).

No que respeita à adolescência, é já um lugar-comum a afirmação de que se trata de um período que envolve a vivência de riscos e desafios muito associados à experimentação de condutas que não haviam sido tentadas antes. $\mathrm{O}$ modo como essas experiências são vividas pode ocasionar efeitos de natureza oposta. Lidar de modo eficaz com os riscos e desafios constitui um importante contributo para o enriquecimento psicoafectivo e para a socialização do adolescente (Direção Geral de Saúde, 2006), e favorece a manutenção de um estilo de vida saudável. Ao invés sucumbir a situações de consumo de substâncias (álcool, tabaco, drogas, medicamentos), ser vítima de violência, sofrer de desordens alimentares, viver insucesso e abandono escolar, maternidade e paternidade precoces, contrair doenças sexualmente transmitidas e realizar tentativas ou mesmo a consumação de suicídio são indicadores de precarização da saúde e do bem-estar, comprometendo, muitas vezes, a própria vida dos adolescentes (Machado \& Silva, 2009; Simões, 2010).

Muitas das experiências mal sucedidas são associadas a jovens que residem em contexto de bairro social, acrescentando-lhes ainda outros rótulos como défice de integração social ou delinquência. Esta representação negativa e bastante vincada da associação entre esse contexto habitacional e juventude minimiza oportunidades de desenvolvimento saudável e acentua o risco da profecia auto-realizada.

\section{Educar os adolescentes para a Sexualidade}

A sexualidade é uma dimensão fundamental da vida humana, com uma função reguladora da saúde física e emocional (Volpi \& Leszczynski, 2008). Expressa-se em práticas e desejos ligados à afetividade, ao prazer, aos sentimentos e ao exercício da liberdade individual (Ramiro, 2013).

A educação sexual pode ser dividida em informal e formal. A primeira caracteriza-se pela aprendizagem com os outros através da observação direta, no contacto com as figuras parentais, outros familiares, educadores, professores, pares e com os meios de comunicação social em geral, ocorrendo de forma espontânea, não intencional. Já a educação sexual formal caracteriza-se por ações estruturadas e intencionais, que visam a aquisição de conhecimentos e o desenvolvimento de competências (Marques, Vilar \& Forreta, 2002), essenciais para a vivência plena, livre e responsável da vida afetiva, pessoal e social (Amor Pan, 1997). Estas duas formas de educação sexual complementam-se, isto é, por um lado, as crianças e os jovens precisam de amor e apoio no seu ambiente social e familiar para desenvolverem a sua identidade sexual, mas também precisam adquirir conhecimentos específicos, atitudes e competências, que devem ser transmitidos por profissionais habilitados para o fazer (Organização Mundial de Saúde \& Federal Centre for Health Education, 2010).
Está bastante fundamentada e justificada a necessidade de práticas de educação sexual, promotoras da vivência positiva da sexualidade (Ramiro, Reis, Matos, Diniz, \& Simões, 2011). A educação sexual formal é cada vez menos encarada como a realização de atividades com carácter predominantemente informativo sobre saúde reprodutiva (Marques, Vilar \& Forreta, 2002), sendo antes pensada no formato de ações que identificam a sexualidade como uma componente positiva do desenvolvimento pessoal, cujas expressões contribuem para o bem-estar pessoal e relacional e não só para a reprodução (Berman, 2010).

Quando falamos em educação sexual na adolescência é necessário ter em conta que esta fase da vida se caracteriza por uma profunda revolução de cariz bio-psico-social e cultural (Sampaio, 2006), com muitos adolescentes a iniciarem ou terem prematuramente a sua primeira experiência sexual. Quanto mais cedo for o início das relações sexuais, menos informação e menos competências sobre a sexualidade os jovens terão, logo é menos provável o uso de métodos contracetivos e, por consequência, maior a probabilidade gravidez precoce e de contração de doenças de cariz sexual (Marques \& Prazeres, 2000; Sampaio, 2006).

Neste quadro, a vivência da sexualidade na adolescência pode representar um risco para a saúde. Rapazes e raparigas devem ter acesso à informação e educação sobre sexualidade e os melhores apoios em matéria de saúde sexual e reprodutiva, mas sem perder de vista a promoção do seu desenvolvimento global (Brás, 2012).

\section{Projeto "Jovens Ativos"}

Partindo, então, da premissa de que a promoção de competências para a vida tem forte potencial na promoção de comportamentos saudáveis, e consequentemente de competências essenciais para a vivência de uma sexualidade saudável e responsável, e da convicção da importância de ações de proximidade, concebeu-se uma intervenção para jovens em contexto de bairro social intitulada Projeto "Jovens Ativos".

Através do Projeto pretendeu-se quebrar estereótipos, ampliar oportunidades de promoção da saúde, facilitar equidade de oportunidades e contribuir para a capacitação de escolhas saudáveis. Com as ações nele compreendidas, assume-se a responsabilidade de promover experiências positivas aos jovens, encarandoos como pessoas ativas, com capacidades criativas e inovadoras, capazes de darem resposta a interesses pessoais e necessidades sociais. As metodologias adotadas são participativas e vivenciais. A intervenção foca-se numa tónica desenvolvimental, no âmbito da qual os jovens acedem a contextos sociais positivos, por meio de iniciativas organizadas especificamente para eles; também interagem com pessoas com competências particulares - como professores, líderes comunitários e /ou mentores. No seu conjunto, estas experiências pretendem também capacitar os jovens para a apropriação de valores associados à saúde e ao bemestar comum (Lerner, et al., 2009 citado por Franco \& Rodrigues, 2014). Pretendem ainda dotar os jovens de mais competências e conhecimentos sobre sexualidade, 
perspetivando a sexualidade como uma componente positiva do desenvolvimento pessoal. Para este efeito em concreto foi concebido no âmbito do Projeto "Jovens Ativos" um Atelier formativo, isto é, uma ação deliberada e estruturada que se descreve sucintamente em seguida.

\section{Método}

\section{Participantes}

O grupo de participantes no Atelier foi constituído por 12 jovens, 6 do sexo masculino e 6 do sexo feminino, de idades compreendidas entre 14 e os 19 (média de 14.9), residentes num bairro social no concelho de Ponta Delgada.

\section{Instrumentos}

Para aferir os conhecimentos dos adolescentes relativos à sexualidade foi construído o "Questionário de conhecimentos sobre sexualidade", composto por oito questões (resposta fechada e aberta). Este questionário foi aplicado no início e no final do Atelier. No final inclui mais uma questão, em formato de resposta Likert, que incidiu sobre a satisfação com a participação. O questionário foi preenchido individual e voluntariamente.

\section{Procedimentos}

O Atelier foi constituído por 10 sessões com a duração média de uma hora e meia cada. Os temas incidiram em áreas de competências para a vida, como sexualidade; VIH/Sida; métodos contracetivos; infeções sexualmente transmissíveis; orientação sexual; comportamentos de risco e violência no namoro e foram trabalhados através de metodologias participativas.

Para se perceber eventuais efeitos do Atelier nos conhecimentos dos jovens e sua adesão às sessões, procedeu-se à análise de cada um dos itens do questionário, comparando as respostas dos dois momentos de recolha. Para as respostas fechadas usouse a seguinte pontuação: $0=$ resposta incorreta; $1=$ resposta incompleta; e $2=$ resposta correta. Para as respostas abertas, o procedimento assentou na consideração das verbalizações dos participantes, agrupando-as apenas quando era clara a referência à mesma ideia (uso das mesmas palavras) por parte dos jovens. No caso das respostas abertas, cada jovem pode ter indicado mais do que uma ideia.

\section{Resultados}

As Figuras 1 e 2 ilustram as respostas pré e pós Atelier à questão aberta "O que entendes por sexualidade?"

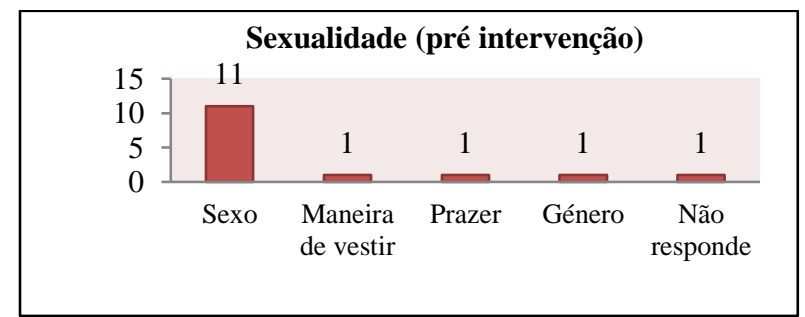

Figura 1. O que entendes por sexualidade? [Pré]

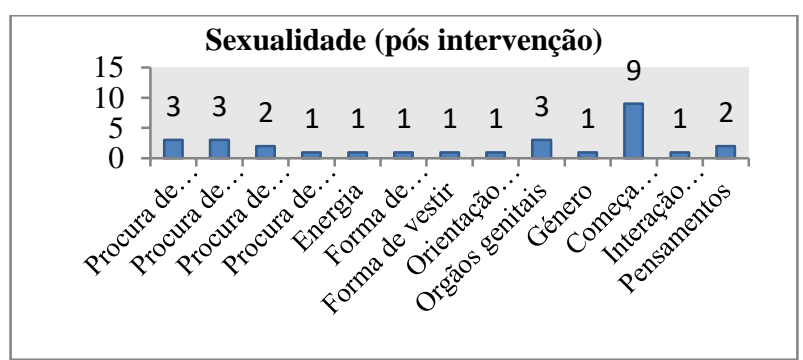

Figura 2. O que entendes por sexualidade? [Pós]

Observa-se que antes da participação no Atelier a maioria das respostas dos jovens associava a sexualidade a sexo, no sentido restrito de prática de relações sexuais, enquanto no final da formação a maioria das repostas reflete o próprio ciclo de vida do ser humano e contempla um leque mais amplo de comportamentos, muitos das quais remetem para uma condição de afeto, ausente no levantamento inicial.

A Figura 3 ilustra as respostas pré e pós Atelier à questão fechada "Através de que fluídos corporais é transmitido o VIH?"

\section{Transmissão do VIH}

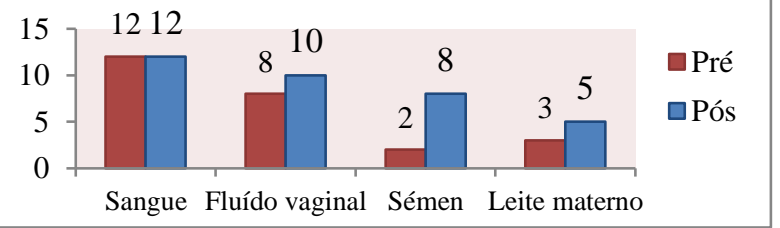

Figura 3. Através de que fluídos corporais é transmitido o VIH? [Pré e Pós]

A observação da Figura 3 permite perceber que os jovens já detinham conhecimento sobre formas de transmissão do VIH, antes de participarem no Atelier. A resposta que mais se alterou foi a relativa ao sémen, o que, no nosso entender, se deveu sobretudo ao desconhecimento deste termo.

A Figura 4 ilustra as respostas pré e pós Atelier à questão fechada "Quais os métodos contracetivos que conheces?"

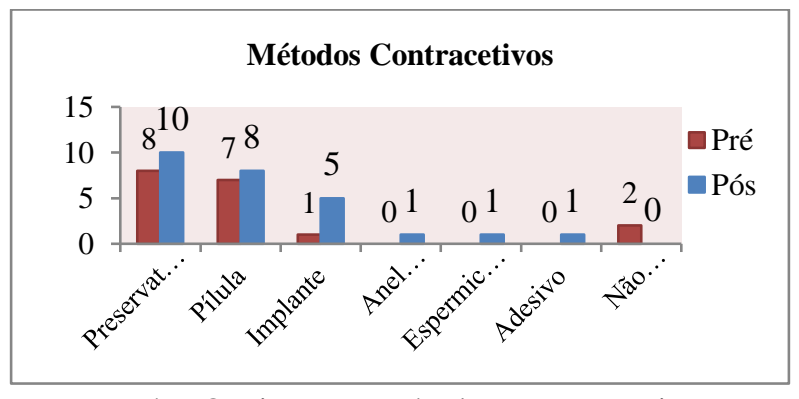

Figura 4. Quais os métodos contracetivos que conheces? [Pré e Pós]

A leitura da Figura 4 indica ampliação do leque de conhecimento de métodos contracetivos com a frequência do Atelier. No primeiro levantamento foram identificados três métodos, enquanto no segundo foram 
identificados seis métodos. O método contracetivo mais conhecido pelos jovens foi o preservativo.

A Figura 5 mostra as respostas pré e pós Atelier à questão aberta "Identifica quantos e quais os métodos que previnem a transmissão de IST's?"

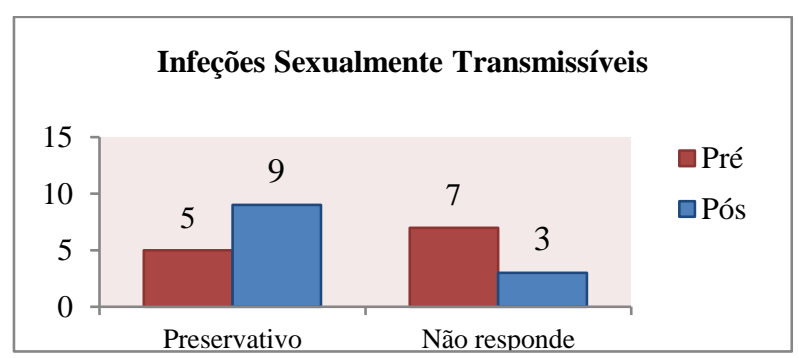

Figura 5. Identifica quantos e quais os métodos que previnem a transmissão de IST's? [Pré e Pós]

A observação da Figura 5 indica que mais 4 jovens aumentaram o seu conhecimento no que diz respeito à prevenção da transmissão das IST's.

A Figura 6 mostra as respostas pré e pós Atelier à questão aberta "Quais as orientações sexuais que conheces?"

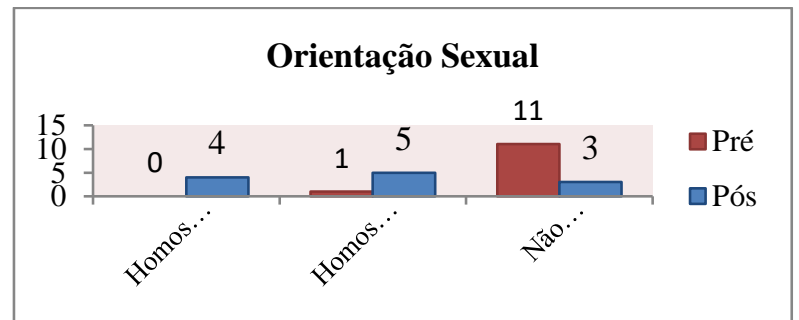

Figura 6. Quais as orientações sexuais que conheces? [Pré e Pós]

A Figura 6 ilustra que a temática orientação sexual foi uma das que os jovens apresentaram maior desconhecimento antes da formação.

A Figura 7 apresenta as respostas pré e pós Atelier à questão aberta "O que entendes por comportamentos de risco?"

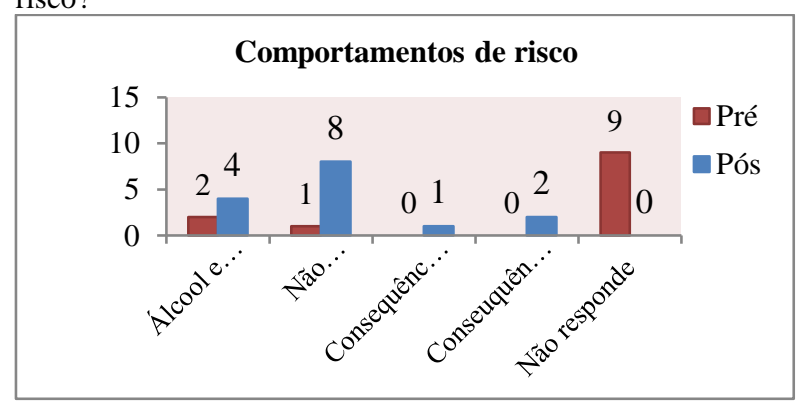

Figura 7. O que entendes por comportamentos de risco? [Pré e Pós]

Comentando a Figura 7, no primeiro levantamento a maior parte dos jovens não respondeu à questão, eventualmente por desconhecimento. No segundo levantamento, os jovens identificam a não utilização de métodos contracetivos como um comportamento de risco, seguindo-se o consumo de álcool e outras drogas. Identificam ainda que estes comportamentos têm consequências perigosas, inesperadas e negativas, para a sua saúde.

A Figura 8 mostra as respostas pré e pós Atelier à questão aberta "A violência doméstica é um crime público, pelo que, todas as pessoas que tenham conhecimento de uma situação deste género a devem reportar?"

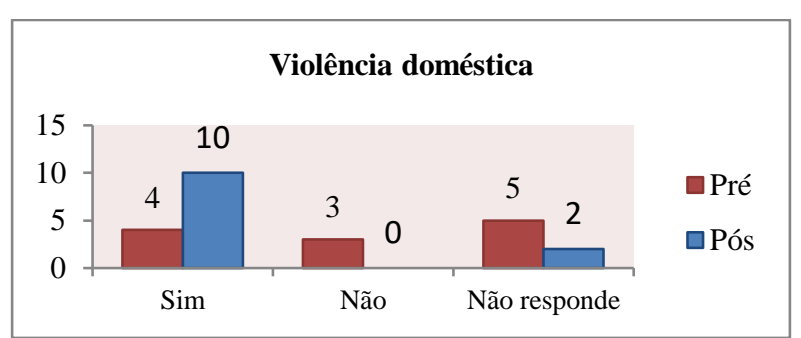

Figura 8. A violência doméstica é um crime público, pelo que, todas as pessoas que tenham conhecimento de uma situação deste género a devem reportar? [Pré e Pós]

A leitura da Figura 8 indica que no primeiro levantamento apenas 4 jovens sabiam que a violência doméstica é um crime público e que o deveriam reportar, 5 jovens não responderam e 3 responderam de forma errada. Após a participação no Atelier, 10 dos 12 jovens responderam acertadamente.

A Figura 9 exibe o grau de satisfação pela frequência do Atelier.

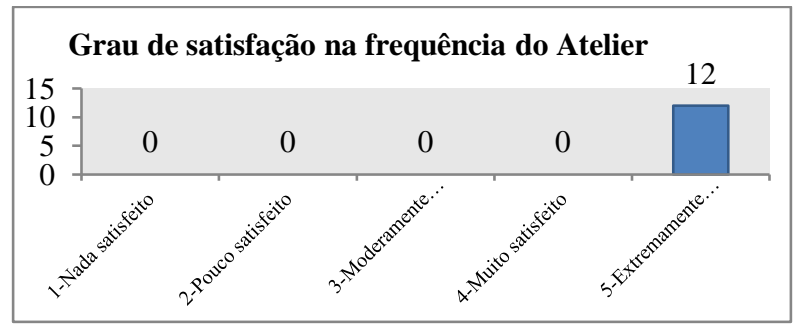

Figura 9.Qual o teu grau de satisfação pela participação no Atelier formativo de educação sexual?

A observação da Figura 9 sugere que todos os adolescentes manifestaram elevada satisfação pela frequência e participação no Atelier

\section{Discussão}

As respostas dos jovens mostraram que a participação no Atelier contribuiu para expandir o entendimento do conceito de sexualidade, inicialmente muito circunscrito ao ato sexual e posteriormente já pensado em termos do ciclo de vida e abrangendo as dimensões afetiva e cognitiva. Depreende-se, destes resultados que, apesar das diversas fontes de informação sobre esta matéria e da fácil acessibilidade às mesmas, como é o caso da internet, é benéfica a existência de uma exploração orientada do tema, numa lógica de proximidade aos jovens. As ações de educação sexual realizadas nas escolas ainda ocorrem de forma pontual, espaçada e para grupos de elevada dimensão, condições que, provavelmente, subtraem força ao seu efeito junto dos jovens. 
As respostas dos jovens mostraram ainda os assuntos prioritários a trabalhar, isto é, aqueles em que há evidência de maior desconhecimento. Apesar da educação sexual ter vindo a ganhar maior preponderância, parece ainda haver conhecimento que não é igualmente partilhado por todos. Para estes jovens, tópicos como os métodos contracetivos, a prevenção de doenças sexualmente transmissíveis e a identificação de comportamentos de risco no domínio da sexualidade merecem uma atenção especial. A precariedade dos conhecimentos sobre sexualidade contribui para o aumento dos riscos nas experiências sexuais, potenciando situações de gravidez na adolescência ou contração de infeções sexualmente transmissíveis.

Em termos de competências mais amplas para a vida e de desenvolvimento de valores associados à saúde e ao bem-estar comum, os tópicos referentes à orientação sexual e à violência doméstica afiguram fazer sentido para este grupo de participantes. No primeiro caso, entre outros aspetos, os jovens manifestaram desconhecer as designações corretas, apoiando-se em nomeações populares carregadas de preconceito negativo. No segundo caso, o desconhecimento das implicações legais deste tipo de comportamento abusivo poderá contribuir para a banalização e minimização de situações de violência doméstica, fenómeno que urge erradicar no paradigma de uma sociedade justa $\mathrm{e}$ equitativa. A precariedade dos conhecimentos sobre estes tópicos pode facilitar comportamentos discriminatórios, preconceituosos e violentos nas relações íntimas.

Com base na literatura consultada e que inspirou esta ação, conjugada com a observação direta da realidade de vida dos jovens e com a plena expressão de agrado destes sobre a sua participação no Atelier, acreditamos que este tipo de intervenção de proximidade, em pequeno grupo e em que os jovens vão, gradualmente, ficando mais conhecedores e sendo modelos e mentores para os mais jovens é uma via para quebrar estereótipos, ampliar oportunidades de promoção da saúde, facilitar equidade de oportunidades e contribuir para a capacitação de escolhas saudáveis em públicos com maior vulnerabilidade social.

\section{Referências Bibliográficas}

Amor Pan, J. R. (1997). Afectividad y Sexualidad en la Persona com Deficiencia Mental. Madrid, Publ. Universidad Pontifícia Comillas, Catedra de Bioetica, $\mathrm{n}^{\circ} 2$.

Brás, F. (2012). "Sexualidade na Adolescência: Análise da Perspetiva do Adolescente Face à Sexualidade". Dissertação de Mestrado, Escola Superior de Tecnologia e Gestão, Instituto Politécnico de Bragança, Bragança, Portugal. http://hdl.handle.net/10198/8008

Berman, L. (2010). Educação Sexual. Como falar com os seus filhos sobre sexo. Londres: Dorling Kindersley.

Direção Geral de Saúde. (2006). Programa Nacional de Saúde dos Jovens 2006-2010. https://www.dgs.pt/paginas-de-sistema/saude-de-a-az/saude-escolar/ficheiros-externos/programa-nacionalde-saude-dos-jovens-pdf.aspx

Franco, G., \& Rodrigues, M. (2014). Programa de Intervenção na Adolescência: Considerações sobre o Desenvolvimento Positivo do Jovem. Temas em Psicologia, 22(4), 677-690. DOI:10.9788/TP2014.401 (http://pepsic.bvsalud.org/pdf/tp/v22n4/v22n04a01.pd $\mathrm{f}$

Machado, F. L. \& Silva, A. (2009). Quantos Caminhos Há no Mundo? Transições para a Vida Adulta num Bairro Social. Cascais: Principia Editora.

Marques, A., Vilar, D., \& Forreta, F. (2002). Educação Sexual no $1^{\circ}$ Ciclo. Um Guia para Professores e Formadores. Lisboa: Texto Editora.

Marques, A. M. \& Prazeres, V. (2000). Educação Sexual em Meio Escolar: Linhas orientadoras. Ministério da Educação e Ministério da Saúde. 6, 510. Lisboa.

Ministério da Saúde (2002). Secretaria de Políticas de Saúde. Projeto Promoção da Saúde. As Cartas da Promoção da Saúde. Brasília: Ministério da Saúde. http://bvsms.saude.gov.br/bvs/publicacoes/cartas_pro mocao.pdf

Monteiro, M. (2011). Competências para a Vida em Adolescentes: Avaliação da qualidade de vida relacionada com a saúde e da competência social. Dissertação de Mestrado, Departamento de Psicologia, Faculdade de Ciências Humanas e Sociais, Universidade do Algarve. Faro, Portugal. https://sapientia.ualg.pt/bitstream/10400.1/1519/1/Co mp\%20para\%20a\%20Vida\%20Adolescentes.pdf

Organização Mundial de Saúde \& Federal Centre for Health Education, BZgA Cologne. (2010). Standards for Sexuality Education in Europe. http://www.oif.ac.at/fileadmin/OEIF/andere_Publikati onen/WHO_BZgA_Standards.pdf

Sampaio, D. (2006). Lavrar o Mar (1. ${ }^{a}$ Edição). Lisboa: Editorial Caminho.

Simões C. (2010). Adolescentes e comportamentos de saúde. $\quad$ Alicerces, 3(3), 223-41. http://hdl.handle.net/10400.21/769

Ramiro, L. (2013). A educação sexual na mudança de conhecimentos, atitudes e comportamentos sexuais dos adolescentes. Dissertação de Doutoramento, Faculdade de Motricidade Humana da Universidade Técnica de Lisboa, Lisboa, Portugal. https://www.repository.utl.pt/bitstream/10400.5/5862/ 1/Lucia_Ramiro_Dout.pdf

Ramiro, L., Reis, M., Matos, M. G., Diniz, J. A., \& Simões, C. (2011). Educação sexual, conhecimentos, crenças, atitudes e comportamentos nos adolescentes. Revista Portuguesa de Saúde Pública, 29(1) 11-21. https://doi.org/10.1016/S0870-9025(11)70003-7

Volpi, S.; \& Leszczynski, S. (2008). Evolução da sexualidade e as causas e consequências de sua repressão ao longo do desenvolvimento físico, energético e emocional: perspectiva psico-corporal. Actas do Encontro paranaense, Congresso Brasileiro, Convenção brasil/latino-américa, XIII, VIII, II (pp. 18). Curitiba, Brasil. 
PONTE, ROCHA, CALDEIRA

http://www.centroreichiano.com.br/Anais\%202008/Sa

ndra\%20Mara\%20Volpi\%20e\%20Sonia.pdf 